Bangladesh J. Sci. Res. 29(1): 55-62, 2016 (June)

\title{
DEVELOPMENTAL DISABILITIES OF CHILDREN AND THEIR HEALTH OUTCOMES
}

\author{
Md. Rasheduzzaman Mondol*, Muhammad Tanvir Faysol ${ }^{1}$ and Md. Shaheen Sikder \\ Department of Nephrology, Holy Family Red Crescent Medical College Hospital, \\ 1 Eskaton Garden Road, Dhaka -1000, Bangladesh
}

\begin{abstract}
A study was conducted among 155 mothers of disabled children. The health outcome of disabled children in Bangladesh focuses overall on their health status. The cross sectional study was carried out in Bangladesh Protibondhi foundation and Society for the welfare of the Intellectual disability from august 2014 to March 2015. The analysis shows that age of most of the mothers of disabled children were between 30 and 39 years and the disabled children were their first baby. The mothers who had less than 3 antenatal visits have a great chance of having a developmental disabled child. Among 155 respondents, 27 per cent had autism and 72.9 per cent had other disabilities (Cerebral palsy, Down syndrome and intellectual disability). 35.5 per cent blood groups of fathers and mothers of children with developmental disabilities have different positive blood groups. After birth weight of 58.71 per cent baby with developmental disabilities were from $1.00-2.00$ $\mathrm{kg}$ which is a low birth weight. About 70 per cent of mothers have not given exclusive breastfeeding to their disabled child. Only 29 per cent of mothers have given exclusive breastfeeding. There is a significant relationship between having delivery without skilled birth attendants and health outcomes of children. 57.7 per cent mothers with disabilities (Cerebral palsy, intellectual disability and Down syndrome) and 42.3 per cent mothers who had deliveries through non-skilled birth attendants gave birth to autistic babies. $9.1 \%$ mothers having history of violence during pregnancy gave birth to autistic babies and $90.9 \%$ mothers having history of violence during pregnancy gave birth to babies with other disabilities.
\end{abstract}

Key words: Developmental disabilities, health outcomes

\section{Introduction}

Disability is a universal element in the human condition to which no one is immune. Many people in Bangladesh view disability as a curse and a cause of embarrassment to the family. In Bangladesh, there have been only a few systematic interventions to raise awareness of persons with disabilities at the community level (Mahmud and Hossain 2005). The number of people with disabilities in Bangladesh is high enough to merit special attention.

In the world around $15 \%$ of total population are living with disabilities, of which almost 2 million of people are visually challenged (Bhattacharjee 2007). Socially these people face discrimination due to social barriers and socio-psychological problems of society, which have negative impacts on all aspects of their life. They are excluded from their society and are unable to

*Author for correspondence: < dr.rasheduzzzaman.52582@gmail.com>. ${ }^{1}$ Department of Medicine, Holy Family Red Crescent Medical College Hospital, 1 Eskaton Garden Road, Dhaka -1000, Bangladesh. 
perform normal daily activities (Scaffa 2003). It has been learned that out of every 94 boys, one is affected by autism. For girls, it is one in every 150. In Bangladesh, almost no research has been carried out on autism. However, about 3,00,000 children have been identified to be affected by autism (Autistic Children's Welfare Foundation 2011).

It is estimated by the Ministry of Social Welfare, Government of Bangladesh, that the total number of persons with autism spectrum disorders could be as high as 0.4 million, of whom only a few hundred have been diagnosed. Another estimate indicates that one in every 500 children in Bangladesh is suffering from autism, meaning that the approximate number of children with autism spectrum disorders in Bangladesh is no less than 2,80,000. The general attitude towards autism is mostly negative and it is seen as a social barrier (Zerin 2014). In industrialized countries governments play a significant role in funding and supporting people with disabilities which include people with autism spectrum disorders. The Bangladesh government has in recent years taken a positive step towards providing essential services and education to children with disability, particularly children with autism spectrum disorders. The government is also providing basic funding for therapeutic and educational needs. However, the support is limited, which indicates that recognition of autism as an important issue needs to be addressed adequately (Efa 2015).

The study reveals that parents are mainly concerned about their children with autism in urban area. Besides, electronic and print media plays an important role to raise awareness on these issues. Non Government Organizations (NGO) and Foreign Agencies are also working for awareness building in this regard. Ministry of Social Welfare on behalf of Bangladesh Government is playing a vital role for providing education to the student with disabilities as well as autism in accordance with their special needs (Hossain 2010). The current perspective is that people with developmental disabilities should not just live in society, but also be valued, accepted, respected and involved.

They should be a vital part of the community - not simply reside in it. Inclusion of people with developmental disabilities in all aspects of community living is the overarching vision of the future (Roebuck et al. 2008). Misconceptions about the health of people with disabilities have led to assumptions that people with disabilities do not require access to health promotion and disease prevention (U.S. Department of health and human services 2000). Evidence shows that health promotion interventions such as physical activities are beneficial for people with disabilities. But health promotion activities seldom target people with disabilities and many experience multiple barriers to participation (Hoffman 2007). Recent studies have shown that a wide variety of prenatal stress from anxiety and partner relationship problems, to natural disasters, increase the risk for a diverse range of adverse neuro-developmental outcomes in the child. These include impaired cognitive development and behavioral problems, autism and schizophrenia (O'Donnell et al. 2009).

Infants of depressed mothers had lower birth weight than those of non-depressed mothers. The relative risk for LBW $(<$ or $=2500 \mathrm{~g})$ in infants of depressed mothers was 95 per cent. The association remained significant after adjustment for confounders by multivariate analyses 
(Rahman et al. 2007). The convention on rights and person with disabilities and the Millennium Development Goals can provide countries with rationale and support to improve availability of health care for people with disabilities. The CRPD indicates the following areas for action: Accessibility, affordability, availability and quality to ensure the right to education as well as equal right and opportunity for the people with disability (Zerin 2014). In reality they are being deprived from a basic human right like right to education(United Nations 2014).

Chronic disability manifests before age 22 and is likely to continue indefinitely. Common types of developmental disabilities are Autism, Cerebral palsy, Down syndrome, Fragile $x$ Syndrome, Intellectual disability, Epilepsy, and Prader-Willi syndrome (Jenkins 2013). Many people in Bangladesh view persons with disabilities as a curse and a cause of embarrassment to the family. Women with disabilities are particularly vulnerable to social discrimination and neglect. In Bangladesh, the health care service, delivery system and approaches do not include medical rehabilitation for persons with disabilities.

Persons with disabilities need many facilities for rehabilitation therapy and medical care assistance which are inadequate in the country. There are approximately six times more persons with disabilities in rural areas than urban. Rural persons with disabilities have no other alternative than to turn to traditional, often inappropriate or inadequate treatment. In addition, non-institution based rehabilitation or community-based rehabilitation (CBR) are being implemented (JICA Planning and Evaluation Department 2002). First and foremost, policy makers must make provisions for persons with disabilities themselves to actively participate in policy making. At the same time rehabilitation and employment-promotion activities should be implemented and supported. The disabled children in Bangladesh are phenomenal, which cannot be ignored or sidelined because disabled children are significant amount of population which can contribute to the growth and development of the nation if sensibly and sensitively handled.

Given the above background the present research attempts to identify a causal connection between mothers' health and children with disabilities.

\section{Materials and Methods}

The study aims to assess the health outcomes of disabled children in Bangladesh which focuses on overall health status of children with disability and their mothers' health. It was conducted in two different schools of disabled children in Dhaka between August, 2014 to March, 2015 and the sample size was 155 .

A pretested structured self-administered questionnaire was used to collect data from selected samples. The primary data was collected from field investigation through institutional survey. Standard questionnaire and checklists were prepared for collecting relevant information from the institution. Written consents were taken from the respondents and authorities of study population. After that a code plan was prepared using an appropriate coding system and database was developed using Microsoft Excel for the purpose of data entry. Samples were analyzed by using SPSS software 18.0 version. 


\section{Results and Discussion}

The age of children with developmental disabilities varied from $5-15$ years. Mean age is 10.86 years. 14.8 per cent having age 15 years was the highest number in this group. It is evident that mothers of children with developmental disabilities were married between the ages of 16 and 20 years that were 36.1 per cent and was highest in number.

Table 1. Distribution of types of disabilities.

\begin{tabular}{lcc}
\hline Types of disability & Frequency & Per cent \\
\hline Autism & 42 & 27.1 \\
Other disabilities & 113 & 72.9 \\
(Cerebral palsy, Down syndrome, intellectual disability) & & \\
Total & 155 & 100.0 \\
\hline
\end{tabular}

Among 155 respondents 27 per cent had autism and almost 73 per cent had other disabilities (Cerebral palsy, Down syndrome and intellectual disability).

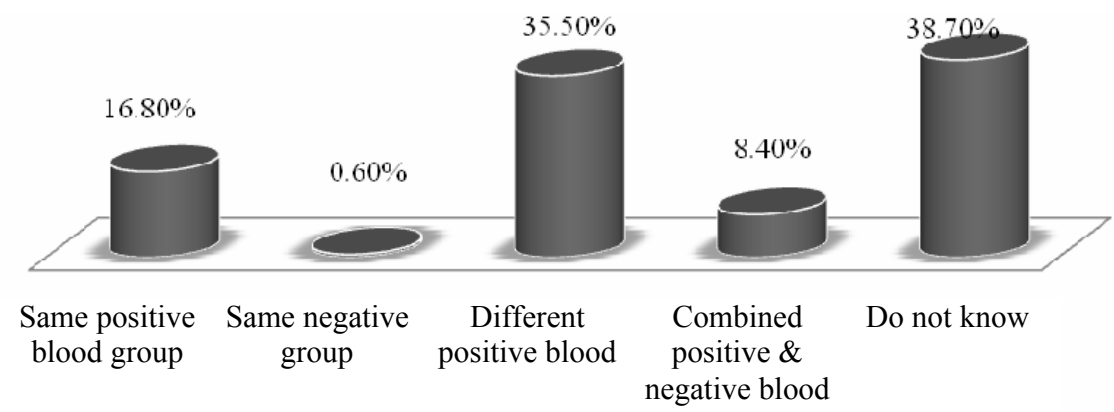

Fig. 1. Distribution of blood groups of fathers and mothers of children with developmental disabilities.

About 35.5 per cent of fathers and mothers of children with developmental disabilities have different positive blood groups. Same negative has the lowest percentage among all the blood groups which is 0.6 .

It shows that 60 per cent of mother's modes of delivery were normal vaginal delivery at the time of giving delivery of disabled children and only 36.8 per cent of mother's modes of delivery were cesarean section at the time of giving delivery of disabled children. It was also found that 3.2 per cent mothers who delivered their babies by other processes also gave birth to disabled children.

After birth weight of 58.71 per cent babies with developmental disabilities were from 1.00 $2.00 \mathrm{~kg}$ in weight group. Mean weight of all babies is $2.22( \pm 0.82)$. 


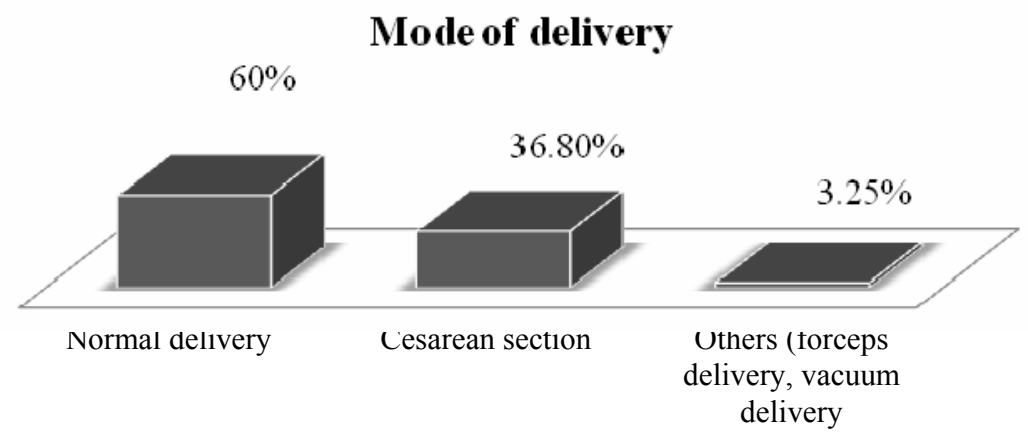

Fig. 2. Distribution of mode of delivery.

Table 2. Distribution of weight of disabled children in $\mathrm{kg}$.

\begin{tabular}{lcc}
\hline Weight of baby $(\mathrm{kg})$ & Frequency & Per cent \\
\hline $1.00-2.00$ & 91 & 58.71 \\
$2.10-3.00$ & 39 & 25.16 \\
$3.10-4.00$ & 21 & 13.55 \\
$4.10-5.00$ & 4 & 2.58 \\
Total & $\mathbf{1 5 5}$ & $\mathbf{1 0 0}$ \\
\hline
\end{tabular}

Mean weight of all babies $2.22 \mathrm{~kg}(\mathrm{Sd} \pm 0.82)$.

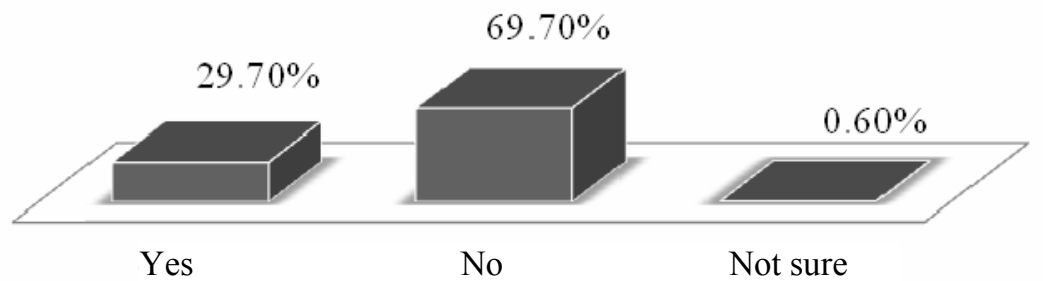

Fig. 3. Distribution of exclusive breast feeding of disabled child.

About 69.7 per cent of mothers have not given exclusive breastfeeding to disabled children and only 29.7 per cent of mothers have given exclusive breastfeeding.

45.8 per cent of children with disability suffered from birth asphyxia during delivery and 42.6 per cent of disabled children were not suffering from birth asphyxia during delivery. About 11.6 per cent mothers were not sure about birth asphyxia. 


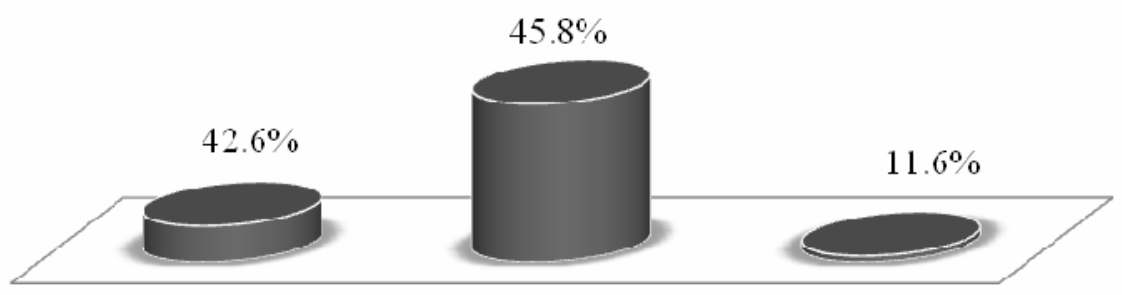

Fig. 4. Distribution of birth asphyxia of children.

Table 3. Association between the mode of deliveries through non skilled (NSBA) and skilled birth attendants (SBA) with health outcomes of their disabled children.

\begin{tabular}{|c|c|c|c|c|c|c|c|c|}
\hline \multirow{3}{*}{ Delivery } & \multicolumn{4}{|c|}{ Health outcome of disabled children } & & & \multirow[t]{3}{*}{$\chi^{2}$} & \multirow[t]{3}{*}{$\mathrm{p}$ - value } \\
\hline & \multicolumn{2}{|c|}{ Autism } & \multicolumn{2}{|c|}{ Other disabilities } & \multicolumn{2}{|c|}{ Total } & & \\
\hline & Freq. & Per. & Freq. & Per. & Frequency & Percentage & & \\
\hline NSBA & 11 & 42.3 & 15 & 57.7 & 26 & 100 & \multirow{3}{*}{3.659} & \multirow{3}{*}{0.088} \\
\hline SBA & 31 & 24.0 & 98 & 76.0 & 129 & 100 & & \\
\hline Total & 42 & 27.1 & 113 & 72.9 & 155 & 100 & & \\
\hline
\end{tabular}

57.7 per cent other disabilities (Cerebral palsy, intellectual disability and Down syndrome) were found among the mothers who had deliveries through non-skilled birth attendants while 76 per cent mothers are found among those who had deliveries through skilled birth attendants. $90.9 \%$ mothers having history of violence during pregnancy and $68 \%$ mothers having no history of violence during pregnancy gave birth to babies with other disabilities.

Table 4. Association between violence against woman during pregnancy with health outcomes of their disabled children.

\begin{tabular}{|c|c|c|c|c|c|c|c|c|}
\hline \multirow{3}{*}{$\begin{array}{l}\text { Violence } \\
\text { during } \\
\text { pregnancy }\end{array}$} & \multicolumn{4}{|c|}{ Health outcome of disabled children } & & & \multirow[b]{2}{*}{$\chi^{2}$} & \multirow[b]{2}{*}{$\mathrm{p}$ - value } \\
\hline & \multicolumn{2}{|c|}{ Autism } & \multicolumn{2}{|c|}{$\begin{array}{c}\text { Other } \\
\text { disabilities }\end{array}$} & \multicolumn{2}{|c|}{ Total } & & \\
\hline & Freq. & Per. & Freq. & Per. & Frequency & Percentage & \multirow{4}{*}{6.881} & \multirow{4}{*}{0.008} \\
\hline Yes & 3 & 9.1 & 30 & 90.9 & 33 & 100 & & \\
\hline No & 39 & 32.0 & 83 & 68.0 & 122 & 100 & & \\
\hline Total & 42 & 27.1 & 113 & 72.9 & 155 & 100 & & \\
\hline
\end{tabular}

From linear regression it has been found that there is a significant relationship between violence during pregnancy and health outcomes of children. If the mother faces violence (physical and psychological) during pregnancy there may be chance of developmental disabilities (Hoffman 2007). Cross tabulation did not show any relationship between conduction of delivery without 
skilled birth attendants and health outcomes of disabled children but linear regression table shows that there is a significant relationship. If delivery is not in right time and right process and without skilled birth attendants, there is a chance of developmental disabilities. Violence against women in Bangladesh is a wide spread phenomenon. The last national data (BBS 2011) on violence against woman (VAW) indicates that more than 87 per cent married women reported experiencing violence in the married life, both physical and psychological.

More than 35 per cent fathers and mothers of children with developmental disabilities have different positive blood groups and 16.8 per cent had same positive blood groups. Sixty per cent of mother's modes of delivery were normal vaginal delivery giving birth to disabled children and only 36.8 per cent mother's mode of delivery was Cesarean Section at the time of giving birth to disabled children.

It was also found that 3.2 per cent mothers delivered their baby by other process like forceps delivery, vacuum delivery. About 70 per cent of mothers have not given exclusive breast-feeding to the disabled children. Another 46 per cent of disabled children suffered from birth asphyxia, and 43 per cent of disabled children did not suffer from birth asphyxia during delivery. In this study it was found that there is a significant relationship between violence during pregnancy and health outcomes of children.

It is important to notice that weight of 58.7 per cent babies with developmental disabilities were from $1.00-2.00 \mathrm{~kg}$. It was also found that there is a significant relationship between delivery without skilled birth attendants and health outcomes of disabled children.

\section{Conclusion}

The present study found that violence during pregnancy and delivery without skilled birth attendants may affect the health outcomes of children which may cause developmental disabilities. Family members are focused on early intervention to prevent the increase of behavioral difficulties and delivery related health problems in children with developmental delay. Disabled children in Bangladesh are phenomenal which cannot be ignored or sidelined because disabled children are a sizable number of population which can contribute to the growth and development of the nation if sensibly and sensitively handled.

Based on the findings the study attempts have been made to provide the following recommendations for future strategies related to disability:

$>$ Antinatal care should be ensured to every mother.

$>$ Delivery through skilled birth attendants.

$>$ Exclusive breastfeeding should be confirmed for every child.

$>$ Raising awareness of people regarding relationship between violence during pregnancy and disability.

Media sensitization should also be used as an increase in awareness of violence against women during pregnancy and disability at community level. 


\section{References}

Autistic Children's Welfare Foundation. 2011. Frequency of Autism, retrieved 25th December. http:// www. acwf-bd.org/frequency_autism.php.

Bhattacharjee, V. 2007. Disaster and Disability in Bangladesh: A Contemporary Review. Paper presented at the International Conference on Tsunami Preparedness of Persons with Disabilities, January, 11 - 12; 2007.

BBS 2011. Bangladesh Bureau of Statistics, Statistics Division, Ministry of Planning, Government of the People's Republic of Bangladesh, Dhaka.

Efa, A.F. 2015. Teachers Understanding of Challenging Behaviours and Management Strategies for Children with Autism Spectrum Disorder in Dhaka city, http://ibrary.crpbangladesh.org:8080/ bitstream/handle/ 123456789/150/5.\%20Farjana\%20Ahmed\%20Efa.pdf? sequence=1

Hoffman, J.M. 2007. Association of mobility limitations with health care satisfaction and use of preventive care: A survey of Medicare beneficiaries. National Center for Biotechnology Information. U.S.

Hossain, A.B.M. Arshad. 2010. The current situation and issues of education for children with Autism : Promoting autism education with perspectives toward a cohesive society. http://www.nise. go.jp/ kenshuka/josa/kankobutsu/pub_d/d-292/d-292_10.pdf

Japan International Cooperation Agency Planning and Evaluation Department (JICA). 2002. Country Profile on Disability People's Republic of Bangladesh.

Jenkins T.L. 2013. Common Types of Developmental Disabilities'. http:/www.examiner.com/article/ common-types-of-developmental-disabilities.

Mahmud Al. R. and J. Hossain. 2005. Disability in Bangladesh Prevalence, Knowledge, Attitudes and Practices'. Unnayan Onneshan. (Center for research and action on development).

O'Donnell K., T.G. O'Connor and V. Glover. 2009. Prenatal stress and neurodevelopment of the child, National Center for Biotechnology Information, U.S.

Rahman A, J. Bunn, H. Lovel and F. Creed. 2007. Association between antenatal depression and low birth weight in a developing country.

Roebuck R, M. Paquet and J. Coultes-Macleod. 2008. Improving Health Outcomes for Children and Youth with Developmental Disabilities, First Leadership Limited.

Scaffa, M. 2003. Competence, Mastery and Independence: Our Cultural Heritage, American Occupational Therapy Foundation Connection, (1), pp. 6-7.

Scott, T. (ed.) 2012. Disaster Preparedness for People with Disabilities. United Spinal Association

United Nations. 2014. The Convention on the Rights of Persons with Disabilities, Training Guide. United Nations publication, 19.

U.S. Department of Health and Human Services. 2000. Healthy people 2010. Understanding and improving health (2nd edition). Washington, DC; U.S: Government Printing Office.

Zerin Afroz, Syeda. 2014. Fostering inclusive education, The Daily Star, May 13, 2014. 